\title{
Chapter 18 Synergies, Trade-Offs and Contextual Conditions Shaping Impacts of the Sustainable Development Goals on Forests and People
}

Wil de Jong, Glenn Galloway, Carol J. Pierce Colfer, Pia Katila, Georg Winkel and Pablo Pacheco

\subsection{Introduction}

The 2030 Agenda for Sustainable Development and its 17 Sustainable Development Goals (SDGs) have been adopted as a follow-up to the 8 Millennium Development Goals (MDGs) that were pursued from 2000 until 2015. There are similarities between the SDGs and the MDGs, but also important differences. Agenda 2030 and the SDGs address a wider array of development challenges, linking them to the broad sustainability agenda, including equitable economic development, social inclusion and environmental protection. Pursuing 17 goals and 169 targets simultaneously implies tremendous challenges in terms of commitment, planning and coordination (Allen et al. 2018). This was recognised when the goals were being formulated, and multiple actors who support the implementation of Agenda 2030 have reiterated the need for integration in implementation. The possibility of positive and negative interactions, or synergies and trade-offs, between both goals and targets were pointed out (ICS 2017).

A body of literature is developing ideas on how to foster successful implementation of Agenda 2030. Authors try to evaluate possible interactions among SDGs when they are being implemented concurrently. Some authors frame this in terms of SDG interactions (ICS 2017; Le Blanc 2015, Nilson et al. 2016), synergies and trade-offs (Katila et al. 2017), while others highlight the need for integration of SDG implementation (Nunes et al. 2018, StaffordSmith et al. 2017, Waage et al. 2015). Allen et al. (2018) identify the need for methods, models and tools that can capture and address the intrinsic complexities of the SDGs, including interactions, synergies and trade-offs, or options for their integration.

The present volume is a contribution to facilitate successful implementation of Agenda 2030 and the SDGs, focusing specifically on forests and 
the people who live in or near them and who depend on them for their material, social, cultural and emotional well-being (from here on referred to as forests and people). The focus on SDGs and forests is not new. Forests constitute several of the major global biomes; they are major contributors of ecosystem services, second only to oceans (Constanza et al. 2014). Forests are important not only for the 1.6 billion people who depend directly on them for their economic and non-material well-being (Chao 2012), but also for the entire human race because of the multiple services they provide, such as sequestering and storing large amounts of carbon and regulating weather patterns. In line with these assertions, most discussions on SDGs and forests address how forests or enhanced forest management can contribute to achieving the SDGs (FAO 2018, Seymour and Busch 2017). In this volume the analysis is reversed in order to explore potential impacts of the SDGs on forests and people.

A few prior studies already warn of likely adverse impacts of SDG implementation on forests (Swamy et al. 2018): for instance, the expansion of road building into forest areas under SDG 9 (Industry, Infrastructure and Innovation) or the expansion of agriculture into forests to achieve SDG 2 (Zero Hunger). These undesirable outcomes are to be expected since some SDGs are linked to factors commonly recognised as direct or indirect drivers of deforestation or forest degradation (Geist and Lambin 2002).

In each of the 17 SDG-focused chapters of this volume, the authors address the questions posed in Chapter 1: How does the pursuit of Agenda 2030, through the implementation of the 17 SDGs and their 169 targets, affect forests and the people who live at forest fringes and who depend on them for their material, social, cultural and emotional well-being? What are the positive and negative interactions among the SDGs and Targets? What are the probable impacts on forests and people? What are the projected repercussions of the possible synergies and likely trade-offs? Finally, what contextual conditions shape all these interactions, and how do they interact with the SDGs?

This chapter is organised as follows. Section 18.2 develops a conceptual model that illustrates the different dimensions of SDG implementation: positive and negative interactions, relevant contextual factors, and their impacts on forests and people. Section 18.3 summarises the evidence provided by the chapters on the impact of individual SDG implementation on forests. Section 18.4 does the same, but shifts the attention to impacts on people. Section 18.5 addresses potential synergies and trade-offs implicit in the implementation of the SDGs, and how contextual conditions influence interactions among SDGs and their subsequent impact on forests and people. 


\subsection{Multi-Layered Impact Pathways of the SDGs on Forests and People}

The purpose of this section is to understand the dynamics or mechanisms by which SDGs influence forests and people. Human agency is a significant factor in the SDGs and how they link with forests and people. We chose to represent these linkages as processes of SDG implementation; when SDGs are implemented, their impacts on forests and people can vary. By 'SDG implementation' we mean the efforts pursued by multiple actors with the specific purpose of achieving one or multiple SDGs or targets. We structure the discussion around different implementation pathways. By 'SDG implementation pathway' we refer to efforts that begin at higher public administrative levels, either international or national, leading to efforts at lower public administrative levels all the way to the lowest level where efforts are expected to have direct impacts. We do recognise that there may be initiatives contributing to Agenda 2030 that do not follow such a linear pathway; however, we argue that these may be in response to what is referred to below as Pathway of Influence 2, shaped by discourses and ethical incentives (Bernstein and Cashore 2012).

One other conceptual positioning that we make here is that we chose to view Agenda 2030 as a global policy and the 17 SDGs as policy instruments to achieve this policy. We recognise that alternative lenses could have been utilised in this analysis - for instance, a systems dynamic perspective or a network conceptual framework (ISC 2017). Agenda 2030 and the SDGs represent global efforts initiated and implemented under the umbrella of the United Nations (UN), endorsed by its member countries and implemented nationally, as well as by multiple international agencies and other groups. As such, Agenda 2030 and the SDGs constitute a global policy regime (c.f. Krasner 1983). International regime theorists are particularly concerned with measuring impacts of international regimes (Humphreys 2016) and have proposed ways to measure such impacts (Sprinz and Helm 1999). In recent years, global governance has gradually taken over from regime theory as the dominant theoretical framework to reflect multiple efforts to govern issues of public interest at global scales. Global governance academic inquiry is more concerned with the complex interactions of actors and international instruments, such as UN conventions and the organisations with mandates to implement. The actions of these organisations are influenced by multiple constituencies, especially groups that are not part of statutory government.

A framework that has been proposed to analyse the impact of international policy instruments is the Pathways of Influence Framework (Bernstein and Cashore 2012, Cashore et al. 2016). This framework distinguishes four 
types of pathways: (1) direct compliance with international policy instruments; (2) following norms that emerge concurrently with the enactment of instruments and that are transmitted via discourses; (3) market-based incentives that encourage compliance with instruments; and (4) direct efforts to support implementation from international actors, such as international non-governmental organisations (NGOs) or overseas development assistance (ODA) organisations (Cashore et al. 2016).

The four Pathways of Influence - as well as international regime theory and global governance theory - recognise that governance efforts of international origin are implemented at national and subnational levels, and that impact analysis needs to reflect this. Formal policy impact monitoring is a welldeveloped field of modern public administration. Such monitoring is quite sector specific: for instance, monitoring of agricultural policies is quite different and is carried out independently from health-sector policy monitoring. This suggests that monitoring progress of SDG implementation will often be carried out on a piecemeal basis, differentiated by single SDGs. For the purpose of this chapter, however, our interest is not in learning the general impacts of SDG implementation but, specifically, their projected impacts on forests and people.

Agenda 2030 places major responsibility for SDG implementation on national governments. Countries are invited to prepare annual voluntary reports on progress with Agenda 2030 and SDG implementation (Kindornay 2018). To date, these are the best officially available accounts of how SDG implementation is taking place. The voluntary reports submitted so far demonstrate a few relevant developments. There is a widespread verbal embrace of Agenda 2030, but countries go about implementing the agenda and the goals via different approaches. Countries prioritise selected SDGs: the majority of countries that submitted voluntary progress reports in 2017 reported on progress on a subset of goals. While the key role of national governments is widely acknowledged, a myriad of other initiatives are underway to contribute to the SDG agenda. Consistent with the prevailing growing interest for the sustainable development idea, the private sector is encouraged to take leadership in this global effort, as is the academic sector through research and education. Many countries still have to adopt the underlying principles of Agenda 2030. For instance, many have not adjusted or integrated national development agendas with these principles. They have yet to identify linkages between SDGs and ongoing national policies, or to adopt integrated policies covering multiple goals (Kindornay 2018).

This state of affairs has important implications for understanding the impacts of Agenda 2030 and the SDGs on forests and people. To date, there is a paucity of empirical evidence to trace implementation, let alone to identify the degree to which integrated implementation of multiple SDGs leads 
to synergies or trade-offs related to forests and people. However, as is done in many of the SDG chapters of this volume, it is possible to draw on prior experiences with similar processes.

We propose a conceptual model that represents how the pursuit of Agenda 2030 and the SDGs will likely impact forests and people. The model is structured as follows. Agenda 2030 and the SDGs follow multiple pathways, and we locate these within the Pathways of Influence Framework. Agenda 2030 and the goals themselves serve as the starting points for the impact pathways. There are multiple agents along the influence pathways, with quite a few operating at the international level with coordinating or supporting functions. This coordination and support targets national governments as they are the mandated bodies to implement Agenda 2030 and the SDGs within each country. There is also a plethora of NGOs operating at multiple public administrative levels that support SDG implementation. We believe it is relevant to consider influences as far down as single forest landscapes to foster understanding of how SDG implementation actually affects forests and people - our primary interest in this volume.

As observed in the voluntary SDG implementation reports (Kindornay 2018), the actors who influence SDG implementation are primarily government actors and civil society organisations who have been given or have assumed co-responsibilities to implement the SDGs. Other actors - for instance, the private sector and forest-dependent community organisations - are likewise adopting the SDG discourse and playing an increasingly important role as they respond to incentives and constraining regulations that emerge from SDG implementation (Pathway 1) and to new discourses emerging from Agenda 2030 (Pathway 2). Private sector actors respond to market signals, related to economic opportunities, but also costs (Pathway 3). In addition, different actors along implementation pathways are experiencing direct influences (Pathway 4); for instance, when external agents undertake projects or training related to SDG implementation.

Key elements of this conceptual model (Figure 18.1) are contextual conditions influencing choices and decisions made along SDG impact pathways that lead to actions and eventual outcomes. According to this model, at the national level governments or their agencies prioritise SDGs, develop coherent and integrated implementation strategies, and allocate resources, responsibility and authority taking, into consideration priorities relating to economic development, nature conservation and social inclusion. The comparative weight placed on these interrelated dimensions of sustainability influences on SDG priority setting would ideally be manifested in: the development of integrated implementation strategies; the actual implementation of separate goals; the successful integration and coherence of efforts that 


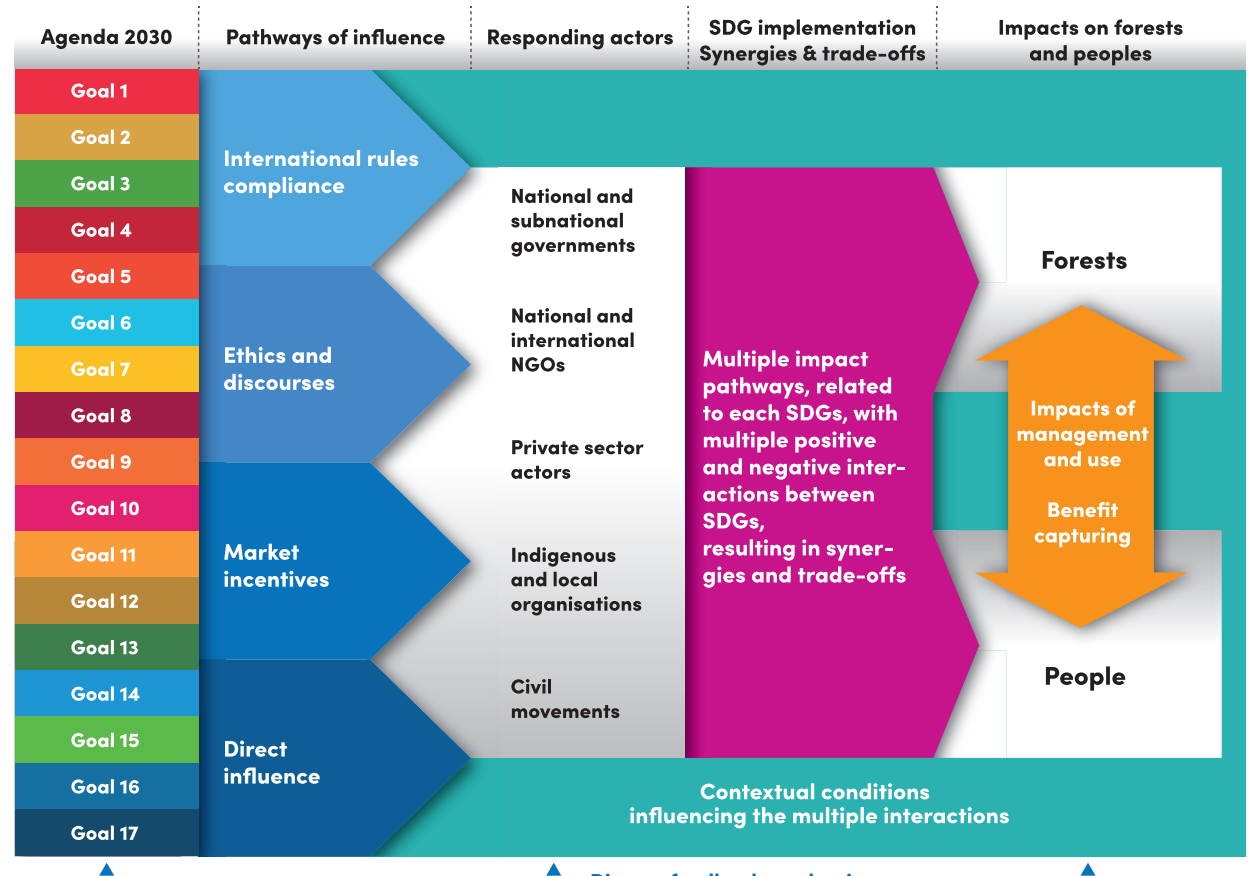

A.

A... Diverse feedback mechanisms

Figure 18.1 Conceptual model representing how the pursuit of Agenda 2030 and the SDGs will likely impact forests and people.

collectively seek to achieve the SDGs; or, even more broadly, the integration and coherence among multiple sectoral policies such that they align within the overarching Agenda 2030.

Contextual conditions play a key role along the SDG implementation pathway. These include a country's national development status and trajectory, or the overall condition of forests. Since contextual conditions vary widely, efforts to understand them are key to developing effective implementation strategies. Because of their recognised importance, many of these conditions are actually targeted by the SDG agenda. Like the SDGs, these conditions do not operate in isolation, but, rather, interact in complex ways. This results in a web of interactions of SDGs and contextual conditions, leading to observed and projected impacts on forests and people. Examples of these interactions are provided in Section 18.5. First, however, we provide a synthesis of how single SDGs and SDG groups are expected to impact forests (Section 18.3) and people (Section 18.4).

Finally, we do suggest feedback mechanisms within the model described above and presented graphically in Figure 18.1. These mechanisms have been built since Agenda 2030 was developed. We do not, however, address these further in this chapter. 


\subsection{SDG Implementation Impacts on Forests}

Agenda 2030 and the 17 SDGs are gaining much momentum. The plethora of communications and initiatives at international and national levels indicate that the agenda and goals are being taken up along a normative pathway of influence (Pathway 2). Agenda 2030 is also gaining traction along Pathway 1, the international rules pathway. All of the countries that endorsed Agenda 2030 are taking action to implement at least part of the agenda, corresponding to a variable number of SDGs and associated targets. Increasing momentum is manifested in voluntary reports on SDG implementation and in numerous other reports on how countries envision SDG implementation (e.g. Schandl et al. 2016 for Malaysia) or on the administrative structure that has been set up to implement the agenda and goals (e.g. Dag Hammerskjold Foundation 2018). The latter example illustrates how Agenda 2030 is achieving influence through Pathway 4, the direct access pathway - for example, a Norwegian NGO is providing support to set up an administrative structure for SDG implementation in Colombia (Dag Hammerskjold Foundation 2018).

\subsubsection{SDGs Contributing to Deforestation and Forest Degradation}

We now turn to the following question: what is the influence of SDG implementation on important drivers of deforestation and forest degradation? The SDGs that can be linked to deforestation or forest degradation are primarily SDGs 1 (No Poverty), 2 (Zero Hunger), 7 (Affordable and Clean Energy) and 9 (Industry, Infrastructure and Innovation). Three less obvious SDGs that may contribute to deforestation and forest degradation are SDGs 5 (Gender Equality), 10 (Reduced Inequalities) and 14 (Life below Water).

The SDG that will arguably have the strongest effect on deforestation and forest degradation is SDG 9. We recognise that large-scale agricultural projects to produce oil palm or cattle are a major contributor to deforestation, while logging and fuelwood collection remain major culprits of forest degradation (FAO 2016). Expanding oil palm and cattle production, however, are not the result of agriculture production that would result from addressing SDGs 1 and 2. They might be a result of efforts carried out under SDG 9, if they are related to any SDG at all. We do recognise that small-scale agriculture can also contribute to deforestation, for instance in sub-Saharan Africa, and this may have implications for how SDGs 1 and 2 are addressed in those regions (Chapters 1 and 2, FAO 2016). The largest threat to forests linked to SDG 9 implementation is undoubtedly infrastructure expansion, which often encourages mega agro-industrial projects such as those referred to earlier. Plans for infrastructure expansions are far reaching, especially in Asia, South and Central 
America and Africa. Likely, many countries will report ongoing infrastructure expansion plans as part of SDG 9 implementation. Infrastructure implementation will directly impact swathes of forests. Moreover, it will increase access to forests currently intact due to their remoteness. For instance, China is implementing the Belt and Road Initiative in much of Asia, but also in Africa and Europe (Rolland 2017). In sub-Saharan Africa, 33 development corridors are planned (Dulac 2013). The Initiative for the Integration of Regional Infrastructure of South America is continuing to expand roads, water ways and hydropower basins across the Amazon (Kis Madrid et al. 2011). These projects, among many others, are having major impacts on forests.

The ultimate impact of such programmes on forests (and on people) will depend greatly on how capacities and interests evolve to preserve or sustainably manage forests made accessible and vulnerable through infrastructure expansion, and the degree to which social and cultural impacts of the programmes are considered and addressed (Allen et al. 2018). If that happens, negative impacts on forests can be significantly reduced.

It is expected that SDG 9 will increase energy consumption from forests, especially when the number and activities of small and medium-sized enterprises are pursued vigorously in low- to middle-income countries (Chapter 9). This will contribute significantly to forest degradation. However, SDG 9 implementation may potentially result in the transformation of value chains that rely on wood, increase economic returns for the use of wood and thereby lead to a reduction of wood harvesting (Chapter 9).

The impact of SDGs 1 and 2 on forests is projected through an expansion of agricultural production in many places, which leads to deforestation and forest degradation. Land-use change driven by agricultural expansion is mostly linked to SDG 2. Achieving SDG 2 implies improving food provision to about a billion undernourished people, a number expected to increase; much of this will require facilitating agricultural production, especially in regions where food insecurity is problematic. To offset this possible environmental cost of SDG 2, Target 2.4 calls for an expansion of food production in such a way that natural habitats are not negatively affected. A major question remains about the extent to which progress can be made to boost the capacities or access to inputs among people who suffer from undernourishment so they are able to boost agricultural outputs while adopting methods that are in line with other SDGs, such as 13 (Climate Action) and 15 (Life on Land). Another challenge is to motivate public administrations charged with facilitating these tasks (Chapter 2).

Global food demand is expected to increase for years to come. According to some estimates, it is expected to double by 2050, driven by increased wealth among large numbers of people especially in Asia. Doubling food production 
in the next 30 years can be expected to result in the conversion of substantial areas of forests into agricultural lands, unless alternative options can be found (FAO 2016). Technological innovation will likely alter these estimates (Henry et al. 2018); however, this may not suffice to meet production needs in locations where undernourishment is most problematic. A growing population in forest areas may be another factor that complicates the relationship between food production and forest protection (Chapter 3), although in tropical forest regions such as the Amazon, for instance, it is the urban population that increases, while the rural population remains largely stable (FAO 2016).

While SDG 1 is not directly focused on food production, it is likely to lead to similar impacts on forests because a high proportion of the global poor live in rural areas, and supporting their emergence from poverty can most readily be achieved by boosting income from agriculture or other natural resourcebased activities. Chapter 1 highlights two important points with regards to efforts to reduce poverty and how these may impact forests. The first focuses on how agriculture-centred strategies exert an influence on forests. This largely depends on where along the forest transition curve the agriculturebased poverty reduction is taking place, and the degree to which forest conservation and the mitigation of negative impacts on forests are specifically considered in national poverty-reduction strategies (Chapter 1).

The second point made in Chapter 1 relates to proposed direct money transfers to people below the poverty line, a widely supported measure under SDG 1. A significant portion of these payments are expected, at least in the short term, to contribute to the expansion of agriculture, resulting in further forest conversion. Remittances (another type of cash transfer) that people receive from relatives who have migrated overseas or to cities can be expected to have the same impact. SDG 10 includes among its targets improving facilities to streamline international remittances. If accomplished, increased investments in agricultural production are to be expected, including forested areas (Chapter 10).

SDG 7 (Affordable and Clean Energy) may result in significant impacts on forests due to mechanisms similar to those described for SDG 9. SDG 7 implementation may have negative and positive impacts on forest cover and forest condition (Chapter 7). Its successful implementation will reduce consumption of woodfuels, offset by increases in the use of hydrocarbon-based fuels or other cleaner energy sources. A reduction in traditional woodfuel use would reduce the negative impact of forest exploitation for energy, which is still significant in many parts of the world (Hosonuma et al. 2012). Future energy trends include turning to improved woodfuels, such as wood pellets, and the use of liquid biomass fuels, such as palm oil-based biodiesel, 
whose production may happen at the expense of forests. These options will replace hydrocarbon consumption to reduce greenhouse gas emissions, thus contributing to SDG 13 (Climate Action, Chapter 13). Switching to these energy sources and energy pathways can in principle be undertaken through sustainable production of biofuels. However, as Henry et al. (2018) suggest, achieving sustainable food production and sustainable bioenergy production is likely not to occur within the planetary boundary limit of 15 per cent of ice-free land designated for bio-production.

\subsubsection{SDGs Contributing to Forest Restoration}

The undesirable impacts described as resulting from trade-offs implicit in the pursuit of different SDGs is counteracted by two of the 17 SDGs: SDG 13 (Climate Action) and SDG 15 (Life on Land). The implementation of these two Goals is primarily expected to have positive impacts on forests, while the impact on forest peoples is less clear. SDG 13 adopts the Paris Agreement of the Parties to the United Nations Framework Convention on Climate Change as its implementation vehicle. The Paris Agreement considers forests as central to the pursuit of reducing carbon emissions into the atmosphere, as well as in the effort to support adaptation efforts where impacts of climate change are felt strongly. The Paris Agreement aims to reduce forest carbon emissions through the Reducing Emissions from Deforestation and forest Degradation and the role of conservation, sustainable management of forests and enhancement of forest carbon stocks in developing countries (REDD+) programme, achieving zero deforestation supply chains, but also through multiple efforts to restore forests and forest landscapes. While not strictly part of the Paris Agreement, multiple global commitments and initiatives are aiming for forest restoration, including the Bonn Challenges, the New York Declaration on Forests, the UN's Forum on Forests Program, the Asia-Pacific Economic Cooperation 2020 Forest Goals and many others (see Chapters 13 and 17).

The extent to which the implementation of SDGs 13 and 15 actually curbs negative impacts on forests brought on by the expansion of agricultural production lands and the expansion of infrastructure remains to be seen. These parallel agendas can be expected to play out and interact in complex ways that will vary greatly by context. Sayer et al. (Chapter 15) are sceptical that efforts planned under SDG 15, primarily intended to boost natural habitat protection and conservation of natural forests, will lead to the transformational change required in a dynamic world. To achieve this, SDG 15 should encourage innovative strategies and governance arrangements that transcend traditional approaches, which have often fallen short of expectations. The authors point out that SDG 15 and the associated targets fail to consider 
options that result in multiple benefits being captured by those (including forest peoples) who are in a position to assure forest integrity (Chapter 15).

Impacts of the implementation of other SDGs on forests can be mixed, depending on the specific SDG and contextual conditions. The pursuit of SDG 6 (Clean Water and Sanitation) will largely have a positive impact on forests, as forests are conserved in upper watersheds for the sake of assuring stable downstream water supply. However, forests may become consumers of huge quantities of water, when fast-growing, dense plantations are grown in watersheds. Forest restoration may not be pursued in some locations to avoid water consumption by forest plantations. Hence, this can be a negative outcome of the implementation of SDG 6 (Chapter 6). Efforts towards achieving sustainable cities (SDG 11) can have negative impacts on forests when there is an increased demand for timber or recreation in sensitive areas is boosted, (Chapter 11), but could be positive if green areas, including water catchments, are established or conserved. Success with the implementation of SDG 3 (Good Health and Well-being) will change demographics in locations where livelihoods rely on agriculture, which may increase the pressure on forests (Chapter 3). The achievement of better health for local people may result in greater fertility and thus increased population pressure; on the other hand, the emphasis on access to women's reproductive rights (Chapters 3, 5) may result in a gradual reduction of family size, as has been observed in many parts of the world. Lopez (2008) documents the adverse effects of HIV/ AIDS on forest management in southern Africa. The implementation of SDG 4 (Quality Education) may improve environmental awareness regarding the impacts of modern societies on natural habitats, including forests (Chapter 4). This in turn may have a positive impact on forests, since knowledge and awareness precedes desired changes in behaviour. Similarly, the implementation of SDG 5 (Gender Equality) may boost concerns for the environment and forests where choices must be made that imply trade-offs between material benefits and environmental health (Chapter 5). At the local level, genderbalanced groups tend to do a better job of forest management than either all-male or all-female groups (Sun et al. 2011); the adverse effects on forest management of ignoring women's knowledge, goals and experience have been repeatedly shown. Similar reasoning applies to reducing inequalities within and across countries (SDG 10). Forest management can be improved when the concerns of various stakeholders are addressed and traditional rights are respected (Chapter 10).

Implementation of SDG 16 (Peace, Justice and Strong Institutions) can be expected to have largely positive outcomes on forests, as conflict, injustice, illegality and institutional vacuums are observed to be major indirect drivers of deforestation and forest degradation in many places (Geist and Lambin 
2002). However, SDG 16 implementation primarily supports governments and upholding the rule of law. The extent to which this actually enhances broad, inclusive forest governance is questioned (Chapter 16). In addition, progress to be achieved under SDG 16 can in some cases lead to detrimental impacts on forests, for instance when armed conflicts are resolved and land use that was constrained during conflict becomes possible or even encouraged as part of peace agreements, as is occurring now in some parts of Colombia (Chapter 16).

A final comment is reserved for SDG 17 (Partnerships for the Goals), which aims to mobilise the means to implement the SDGs by promoting partnerships and cooperation. SDG 17 largely strives to facilitate the implementation of other SDGs, and thus its impact on forests depends very much on which SDG resources will be mobilised. In this light, partnerships and support to further sustainable forest management, forest restoration and forest emission reduction could be tracked. Insofar as such reviews are undertaken and conclusions relevant to forest conservation are integrated into practice, the impact of SDG 17 on forests should largely be positive (Chapter 17).

\subsection{SDG Implementation Impacts on Forest People}

As with the impacts on forests, the pursuit of Agenda 2030 and the 17 SDGs will impact forest-dependent peoples in both negative and positive ways. Changes in forest extent and condition will influence goods and services that people obtain from forests linked to livelihoods and well-being. The impacts that SDG implementation will have on forest people requires a separate discussion because the impact pathways from SDGs to forest-dependent people are substantially different from the impact pathways from SDGs to forests.

We focus primarily on the impact that SDG implementation has on people living in or near forests and who draw importantly from forest ecosystem services for their material or non-material well-being. We consider various pathways through which SDG implementation affects the benefits that people derive from forests. The first refers to SDG implementation with significant (positive or negative) impacts on forest conditions that, in turn, affect goods and services that forests provide to meet livelihood or well-being needs. An example of positive impacts on forests, but negative impacts on people, would be when priority is given to carbon stocks or biodiversity conservation and this results in reduced legal access to forest goods and services by local people. If SDG implementation has negative impacts on forests, that is likely to negatively affect goods and services provision.

The 17 SDG chapters of the book provide examples of this first pathway. Related to people's health, Chapter 3 points out that deforestation and forest 
degradation may, in some instances, increase exposure to infectious diseases. Deforestation and forest degradation influence the abundance and distribution of infectious disease vectors. Ebola, malaria and AIDS are examples of this dynamic (Gonzalez et al. 2008, Pattanayak et al. 2008). Expected changes in vector population dynamics resulting from climate change may exacerbate these trends.

The chapters also identify positive linkages between SDG implementation, the impact on forests and people's well-being. Improved water management (SDG 6) can result in better health for local people, reduced energy use for women who must carry water and improved life expectancy for babies. During the implementation of SDG 11 (Sustainable Cities and Communities), if surrounding forest landscapes are included in urban and peri-urban environmental management, this may have beneficial outcomes for both forests and forest residents. As pointed out earlier, poorly implemented city expansion may result in just the opposite effect and have negative outcomes for both forests and people.

A similar argument can be made for the implementation of SDG 13 (Climate Action) as well as SDG 15 (Life on Land). The implementation of both these SDGs, as already discussed, is likely to result in positive outcomes for forest cover (SDG 13) and forest conditions (SDG 15). However, both outcomes may very well be accomplished at the expense of forest people's well-being. Preserving forests or expanding forests for the sake of safeguarding or enhancing terrestrial carbon stocks, proposed under SDG 13, does have significant potential to generate benefits to forest residents. However, there is justified reason for concern that programmes such as REDD+ or large-scale forest restoration efforts may have negative impacts on forest residents whose forest uses may be unfairly constrained (Brown 2011, Scoones et al. 2013). The same holds true in the case of SDG 15 implementation. Command and control conservation has resulted in declining access to forest benefits among forest residents, or even eviction from locations where people have had long-term ties. Until SDG 15 implementation results in the transformational changes needed, these concerns are certainly warranted (Chapter 15).

We differentiate a second pathway of SDG impact on forest people. These are impacts from the implementation of SDGs that focus on people's conditions and capacities, specifically, SDGs 3, 4, 5, 8, 10 and 16 (Good Health and Well-being; Quality Education; Gender Equality; Decent Work and Economic Growth; Reduced Inequalities; Peace, Justice and Strong Institutions). These goals all aim to address conditions that directly affect people and their ability to beneficially engage in the economic, social, political and cultural life of the societies in which they live. The impact of the pursuit of these SDGs is primarily on people and less on habitats (e.g. forests). As with impacts on 
forests, impacts of SDG implementation on people depend very much on context. Contexts for forest people often include life in remote regions of countries where public administration and public services, performance of institutions and the rule of law differ from less-remote regions. Public institutional presence is often weak, and public services are commonly poor or even lacking altogether. Finally, special interests may apply to these marginalised regions because of conservation interests or wider interests in exploitable forest resources, prospective land for non-forest land use or other natural resources.

A clear challenge for Agenda 2030 and the SDGs relates to the difficulty of service provision to forest people. Notably, this is the case for healthcare and education. The provision of these services is more costly in remote regions and beneficiaries have less capacity to pay for services provided. Working conditions for teachers and healthcare providers are often poor and may even include security risks. At the same time, it can be argued that forest settings offer unique opportunities for both health and education. As for health, the availability of forest-based pharmacopoeia can, and often does, contribute to traditional healthcare provision in remote forest settings. This has already been recognised by many researchers on the topic, but also by healthcare providers. However, the actual adoption of local traditional knowledge into mainstream healthcare has been slow (Cunningham et al. 2008). Equally, traditional knowledge related to the environment could become an important contribution to curriculum development and improved, targeted education among forest people.

Another challenge that emerges from forest people's unique location is related to SDG 5 (Gender Equality). The degree to which gender inequality is a problem varies greatly from one forest context to another, with some Indigenous groups remarkably gender equitable. On the other hand, forest societies each have their own particular social relationships and power relations, including related to gender. Efforts undertaken under SDG 5 to address gender inequality may actually have negative outcomes if the local context is not adequately recognised (Chapter 5). In addition, a major obstacle related to moving forward with gender equality among forest people is that the forest sector, timber industry as well as forest administration, have traditionally been heavily male dominated. This can result in resistance to programmes seeking to enhance gender equality.

The remoteness of forest people jeopardises progress in SDG 8 (Decent Work and Economic Growth). There are fewer economic opportunities in locations that are less connected to mainstream economies. This is especially a challenge in forest settings that are in transition, from largely endogenous economies to economies that progressively rely on economic interactions with 
external markets, including labour markets. In that sense, forest settings pose major challenges for the implementation of SDG 10 (Reduced Inequality). Although remoteness can interfere with efforts to stimulate greater equity, increased interaction between remote populations and dominant national groups can in fact often lead to increased inequity. Dominant groups, such as higher castes in India or Malays in Malaysia, can import hierarchical social views, with local forest dwellers seen as the lowest rung on the social ladder (Bose 2011, Lin 2008).

As for governance issues, the focus of SDG 16, these are more difficult to address in more remote locations, for reasons similar to those given above. The governance issues pertaining to people living in tropical forests are legion (from formal governmental corruption to power plays by 'land grabbing' companies to inequities related to conservation projects). In addition, many of the violent conflicts that continue today play out in forested regions and particularly affect remote forest residents.

\subsection{Impacts across SDGs: Drivers of Synergies and Trade-Offs}

The SDGs and associated targets can have positive and negative impacts on forests and people. Agenda 2030 and the SDG framework have been proposed and designed to achieve positive outcomes for all, including forests and people. As we illustrate, there will be tensions among some goals and targets. While this has to do with how SDG implementation is planned and executed, there is a fair degree of inevitability of negative interactions among some SDGs. If an increase in agriculture production is an unavoidable choice to achieve SDGs 1 (No Poverty) and 2 (Zero Hunger), then this likely will have negative implications for SDG 15 (Life on Land).

Nevertheless, it is also widely recognised that there is tremendous potential for positive or synergistic interactions among SDGs and targets. The chapters in this volume provide ample evidence of this. Decent work (SDG 8) and progress in education (SDG 4) will contribute to improving people's health (SDG 3 ), for instance. Multiple similar positive interactions among the 17 SDGs and their targets can be recognised.

These positive interactions, however, do not necessarily imply positive outcomes for forests and people, which is the topic of interest here. We are very much interested in cases when the implementation of multiple SDGs will lead to probable synergistic outcomes for forests and people, and when there will likely be trade-offs. Understanding these interactions has great relevance to enhance capacity to take SDG implementation decisions that result in win-win outcomes. Furthermore, once the unavoidability of trade-offs can 
be fully recognised, more attractive alternatives can be chosen to mitigate negative impacts (Cashore et al. 2016: 31).

The authors of Chapters 1-17 were asked to explore synergies and tradeoffs related to the particular SDG the chapter addressed, as related to the impact on forests and people. While each chapter carried out this exercise, some did so more than others. Synergies and trade-offs were also extensively discussed during our second author workshop in September 2018 in Alghero, Sardinia. The major overarching conclusion from this rich discussion is that synergies and trade-offs will depend very specifically on the particular impact pathway and the context in which the implementation takes place.

This section summarises what Chapters 1-17 and the participants at the Alghero workshop say about synergies and trade-offs related to SDG implementation and the impacts on forests and people, but also how the synergies and trade-offs and their impacts are influenced by contextual conditions. The section first reflects briefly on general positive and negative interactions among SDGs linking them to forests and people; it then summarises how synergies and trade-offs among SDGs are influenced by context conditions.

\subsubsection{Positive and Negative Interactions among SDGs Related to Impacts on Forests and People}

There is the possibility of negative interactions if the SDGs are looked at pairwise, as has been done in Figure 18.2. This figure suggests how the interactions between two SDGs are expected to have an impact on forests or people. The figure was composed with information provided by the chapter authors, who assessed these interactions from the perspective of the SDG focused on in their chapter. The interactions may be synergistic (green cells), imply trade-offs (red cells), or possibly result in both synergies and tradeoffs (yellow cells). The nature of the interactions is strongly influenced by the contextual conditions discussed in Section 18.5.2. The chapter authors' interpretations are reflected in the rows. The figure suggests, for instance, that the authors of Chapter 1 expect synergistic interactions between the implementation of SDG 1 (No Poverty) and six other SDGs (6: Clean water and Sanitation; 7: Affordable and Clean Energy; 10: Reduced Inequalities; 12: Responsible Consumption and Production; 13: Climate Action; 15: Life on Land). The likelihood of trade-offs is strong with SDGs 2 (Zero Hunger) and SDG 9 (Industry, Innovation and Infrastructure). The interactions with other SDGs may result in synergies, but also require trade-offs. Rows and columns in Figure 18.2 are not identical, for instance because the authors of Chapter 2 (SDG 2 Zero Hunger) expected both synergies and trade-offs resulting from interactions between SDG 2 and SDG 1. 


\begin{tabular}{|c|c|c|c|c|c|c|c|c|c|c|c|c|c|c|c|c|}
\hline SDG & 1 & 2 & 3 & 4 & 5 & 6 & 7 & 8 & 9 & 10 & 11 & 12 & 13 & 14 & 15 & 16 \\
\hline 1 & & & & & & & & & & & & & & & & \\
\hline 2 & & & & & & & & & & & & & & & & \\
\hline 3 & & & & & & & & & & & & & & & & \\
\hline 4 & & & & & & & & & & & & & & & & \\
\hline 5 & & & & & & & & & & & & & & & & \\
\hline 6 & & & & & & & & & & & & & & & & \\
\hline 7 & & & & & & & & & & & & & & & & \\
\hline 8 & & & & & & & & & & & & & & & & \\
\hline 9 & & & & & & & & & & & & & & & & \\
\hline 10 & & & & & & & & & & & & & & & & \\
\hline 11 & & & & & & & & & & & & & & & & \\
\hline 12 & & & & & & & & & & & & & & & & \\
\hline 13 & & & & & & & & & & & & & & & & \\
\hline 14 & & & & & & & & & & & & & & & & \\
\hline 15 & & & & & & & & & & & & & & & & \\
\hline 16 & & & & & & & & & & & & & & & \\
\hline 17 & & & & & & & & & & & & & & & \\
\hline
\end{tabular}

strong potential for synergies
both synergies and trade-offs possible - context dependent
strong likelihood for trade-offs
interaction not considered relevant

Figure 18.2 Potential synergies and trade-offs among the SDGs in relation to forests and people.

One positive conclusion that can be drawn from Figure 18.2 is that, at least according to the chapter authors, the majority of the interactions between SDG pairs is likely to be positive for forests or people, as is suggested by the 139 of the 289 squares in the table that are green, and the 97 squares that are yellow, which suggests synergistic interactions but also possibly trade-offs. These conclusions, however, are tentative, as the colours in Figure 18.2 reflect neither the magnitude of these interactions nor any implications for other SDGs. A red square may very well imply consequences for a swath of green squares (Katila et al. 2014).

More complex multiple linkages can be recognised among SDGs. For instance, the pursuit of SDG 2 (Zero Hunger) is linked to many other SDGs. Progress in this SDG will contribute to progress in many of the other SDGs simply because well-fed people are more capable of undertaking actions that contribute to other SDGs. The pursuit of SDG 1, but also SDG 2, can both have important negative impacts on forests. But, if several related SDGs, such as SDGs 4, 11, 13, 15 and 16 (Quality Education; Sustainable Cities 
and Communities; Climate Action; Life on Land; Peace, Justice and Strong Institutions) are addressed adequately and simultaneously, then the negative impacts on forests that SDGs 1 and 2 may have may be significantly reduced.

Rather than trying to identify the risk of negative interactions among SDGs, a more relevant approach is to try to identify how different SDGs can be mobilised to mitigate negative impacts of particular SDGs. In addition to SDGs 1 and 2, the pursuit of SDG 9 (Industry, Innovation and Infrastructure) is likely to have significant impacts on forests, and very likely on people as well. It is therefore necessary to recognise that where SDG 9 implementation is planned, particular emphasis should be given to other SDGs that are likely to mitigate negative impacts on forests and people. The SDGs that can play this mitigation role with respect to SDG 9 are SDGs 4 (Quality Education), 5 (Gender Equality), 8 (Decent Work and Economic Growth), 10 (Reduced Inequalities), 11 (Sustainable Cities and Communities), 12 (Responsible Production and Consumption), 13 (Climate Action), 14 (Life below Water), 15 (Life on Land) and 16 (Peace, Justice and Strong Institution). The SDGs that have great potential to have positive impacts on forests are SDGs 13 (Climate Action), 14 (Life below Water) and 15 (Life on Land), but they require that special attention be focused on SDGs 4, 5, 8, 11 and 16 .

Summarising the evidence so far, and considering the full range of SDGs, it is possible to differentiate one cluster of SDGs with clear potential for positive synergistic interactions resulting in positive outcomes for forests and people. These are SDGs that primarily address institutions and governance conditions, as well as social conditions. They include SDGs 1 (No Poverty, when focusing on tenure and social protection), 3 (Good Health and Wellbeing), 4 (Quality Education), 5 (Gender Equality), 10 (Reduced Inequalities), 12 (Responsible Production and Consumption), 13 (Climate Action related policies) and 16 (Peace, Justice and Strong Institutions). All these SDGs have high numbers of green cells in Figure 18.2. On the other hand, there is one cluster of SDGs that affect land use directly: SDGs 2 (Zero Hunger), 6 (Clean Water and Sanitation), 7 (Affordable and Clean Energy), 8 (Decent Work and Economic Growth), 9 (Industry, Innovation and Infrastructure), 14 (Life below Water) and 15 (Life on Land). Among SDGs that have important implications for land use, there is a strong likelihood of trade-offs, but also of synergies - as between SDG 6 and SDG 15, or between SDG 7 and SDG 15. This suggests that the outcomes of Agenda 2030 on forests and people will importantly be defined by how the SDGs belonging to the SDG cluster that relates to institution, governance and social conditions are implemented and how much this can steer the implementation of and the interactions among the other SDGs to sustainable outcomes. This will to an important degree imply how potential trade-offs within the second cluster of SDGs can be managed and what the results will be for forests and people. 


\subsubsection{Contextual Conditions, SDGs Impacts, Synergies and Trade-Offs}

The impacts of the SDGs on forests and people, as well as the positive and negative interactions among SDGs and how those affect forests and people, are influenced by what this chapter refers to as contextual conditions. These conditions differ between administrative levels where SDG-related actions take place: national, prefectural or provincial, district or municipal. The latter level in many cases represents the forest landscape scale.

Individual countries are developing their own national SDG implementation strategies while parallel, less-structured initiatives contribute to Agenda 2030. Which strategy a government decides upon will greatly depend on where they are along the national development curve. Countries with low per capita gross domestic product (GDP) or low human development index (HDI) will invest in pursuing SDG 1 (No Poverty), and likely they will try to achieve this by focusing on productive sectors, in which case much effort will also be made to move forward with SDG 9 (Industry, Innovation and Infrastructure) and SDG 8 (Decent Work and Economic Growth). The magnitude of impacts of such Agenda 2030 strategies will depend on how much institutional and governance issues are addressed - i.e. how much attention is given to SDGs $1,3,4,5,10,12,13,16$. We hypothesise that several key national indicators, such as per capita GDP, HDI, foreign direct investment and good governance indicators, eventually might explain the SDG implementation strategies that countries have chosen and their outcomes. Future empirical evidence will be required to prove or disprove this hypothesis.

Causal links can be hypothesised between the impact of SDG implementation and multiple indicators of socio-economic development. The same countries that score high on indicators related to education (SDG 4), good governance (SDG 16), and national equity (SDGs 5, 10) may see fewer negative impacts of those SDGs that are more directly linked to material wellbeing. Often, however, low scores on education, good governance and equity indicators are closely correlated with low per capita GDP, Gini coefficient or low HDI scores (Oliver and Oliver 2018). One might expect that a mitigating effect of education, good governance and equity may become evident when such countries do increase investment in these and related SDGs.

A second set of conditions that we expect will eventually turn out to shape SDG implementation and their impacts on forests and people is the relative influence of the four different pathways of influence in the Bernstein and Cashore (2012) framework. The four different pathways - International rule compliance, Discourses and ethics, Markets incentives and Direct influence (see Section 18.2) - can already be seen to have much relevance for SDG agendas and strategies in many countries. They influence the processes of SDG 
strategy development, and they also strongly influence what happens next. Countries will respond to pressures to implement Agenda 2030 because they will need to report back on progress; national governments or designated agencies will pass this on to lower levels of the administration (Pathway 1). There is a tremendous discursive influence of Agenda 2030 and the SDG framework, at the national level and at subnational levels; this is already mobilising enthusiasm and, ultimately, actions of multiple actors and constituencies in society (Pathway 2). While these forces appear to be unleashing significant bottom-up processes (e.g. in the USA, where they have contributed to the New Green Deal movement), it remains to be seen whether the same will play out in regions where Agenda 2030 is likely to have the greatest impacts on forests and people.

As is the case with the two previous pathways, much of what happens to national SDG strategy implementation will depend on the degree to which market forces influence processes on the ground towards progress on the SDGs (Pathway 3). Finally, countries that are offered and accept external support, not only for national SDG strategy development but also during implementation (Pathway 4), are likely to pay more attention to the institution and governance of SDGs as well as to the other SDGs that improve material well-being.

Implementing the SDGs will be a pluralistic response to different contexts. In any country, there is great variation in what forest landscapes look like, and within these landscapes, great variation exists in socio-cultural, biophysical and economic-institutional realities. These factors, as well as the characteristics of the forest landscape itself, influence how multiple actions related to the SDGs will be planned and implemented and eventually will impact forests and people. The type of forest, its extent and the biophysical condition of the landscape carrying the forest are of major influence. Colfer (2005) concludes that the following conditions seriously affect how external interventions affect forests and people: ownership of forests and land, population pressure, social and cultural diversity, social capital and related conflicts over land, forests or other resources, the mix of management goals that occur within a single forest landscape and forest type. There are many nuances that can be added to these overarching landscape and human conditions and how they possibly influence how pursuing the 17 SDGs impacts forests and people.

Besides the search for overarching conditions that influence the implementation of SDGs, we must also consider the notion that some governments may recognise the value of progressively involving wider constituencies such as local organisations, communities and their government structures as partners in the implementation of the SDGs. Insofar as that happens, the diverse contexts of forest peoples and forests will certainly be more meaningfully taken into account, the SDG implementation outcomes will be more finely tuned and appropriate for local conditions, and hence, likely to be more efficacious in terms of impacts on forests and people. 


\subsection{Conclusions}

Agenda 2030 and the SDGs are a major global collective action to achieve equitable economic development and social inclusion for all, while ensuring environmental protection. The SDGs are meant to achieve these overarching interrelated goals in a concerted fashion, but collective progress will be challenged by inevitable interactions among goals. These interactions will, at times, result in mixed outcomes - for example, if progress on one goal gives rise to negative outcomes for forests and people. This volume seeks to shed light on the types of contextual conditions and circumstances that lead to undesirable trade-offs and those that lead to positive, synergistic outcomes. It does so in hopes of avoiding or mitigating the former and enhancing and reinforcing the latter.

Agenda 2030 and the SDGs can be understood as part of global governance or as an international regime. The Pathway of Influence Framework (Bernstein and Cashore 2012, Cashore et al. 2016) was utilised to illustrate that Agenda 2030 and the SDGs achieve influence along multiple pathways, involving governments striving to implement the SDGs and other actors motivated by the growing emphasis on sustainable development ethics, emerging market incentives and the presence of international development agencies and civil society organisations trying to support efforts domestically and across borders. The framework makes it possible to do justice to multiple efforts to pursue Agenda 2030, in addition to the formal government efforts.

Key central questions serve to guide the development of this volume. How is Agenda 2030 likely to impact forests and people? What are possible synergies and trade-offs among goals and targets? What are the contextual conditions that shape these various interactions? These questions are addressed from the viewpoint of single SDGs in Chapters 1-17 of this volume and the answers are summarised in this chapter (Sections 18.3 and 18.4). The analysis also explores potential positive and negative interactions among SDGs and contextual conditions that influence these interactions (Section 18.5).

Two broad groups of SDGs were differentiated. The first group primarily focuses on institutional, governance and social conditions (1: No Poverty; 3: Good Health and Well-being; 4: Quality Education; 5: Gender Equality; 10: Reduced Inequalities; 12: Responsible Production and Consumption; 13: Climate Action; 16: Peace, Justice and Strong Institutions). Many of these SDGs contribute to what has been termed an enabling environment for inclusive forest management and conservation with associated livelihood benefits (Katila et al. 2014). The second group of SDGs affect land use directly and thus are expected to directly impact forests (2: Zero Hunger; 6: Clean Water and Sanitation; 7: Affordable and Clean Energy; 8: Decent Work and Economic Growth; 9: Industry, Innovation and Infrastructure; 14: Life below Water; 15: 
Life on Earth). Collective progress among the first group of SDGs is expected to result in positive (synergistic) interactions, favouring positive outcomes for forests and peoples. However, particularly poor performance in one or more of these SDGs can undermine progress on the other SDGs, highlighting the non-linear nature of the interactions among these SDGs.

With respect to the second group of SDGs, the potential for trade-offs is high, with important repercussions for forests and people. Understanding the potential for these trade-offs is essential in order to avoid implementation pathways that favour a small subset of these SDGs at the expense of the others. From the perspective of this volume, pursuit of the SDGs should foster the creation of an enabling environment that favours sustainable landscapes on which forests and peoples thrive.

\section{References}

Allen, C., Metternicht, G. and Wiedmann, T. 2018. Initial progress in implementing the Sustainable Development Goals (SDGs): A review of evidence from countries. Sustainability Science, published online May 2018. https://doi.org/10.1007/s11625-018-0572-3.

Bernstein, S. and Cashore, B. 2012. Complex global governance and domestic policies: four pathways of influence. International Affairs 88(3):585-604.

Bose, P. 2011. Forest Tenure Reform: Exclusion of Tribal Women's Rights in Semi-arid Rajasthan, India. International Forestry Review 13(2):220-32.

Brown, M. I. 2011. Redeeming REDD: Policies, Incentives and Social feasibility for Avoided Deforestation. London and New York: Routledge and Earthscan.

Cashore, B., Visseren-Hamakers, I., Caro Torres, P. et al. 2016. Can legality verification enhance local rights to forest resources? Piloting the policy learning protocol in the Peruvian forest context. International Union of Forest Research Organizations (IUFRO) and Yale University's Governance, Environment and Markets (GEM) Initiative.

Chao, S. 2012. Forests peoples: Numbers across the world. Moreton-in-Marsh: Forest Peoples Programme.

Colfer, C. J. 2005. The complex forest: communities, uncertainty, and adaptive collaborative management. Washington. Washington, DC: Resources for the Future and Center for International Forestry Research (CIFOR).

Constanza, R., de Groot, R. and Sutton, P. et al. 2014. Changes in the global value of ecosystem services. Global Environmental Change 26:152-8.

Cunningham, A. B., Shanley, P. and Laird, S. 2008. Health, Habitats and Medicinal Plant Use. In Colfer, C. J. (ed.) Human health and forests: A global overview of issues, practice and policy. London: Earthscan, pp. 35-62

Dag Hammerskjold Foundation 2018. Localising the 2030 Agenda in Colombia. Development dialogue paper 25. Uppsala: Dag Hammerskjold Foundation. 
Dulac, J. 2013. Global land transport infrastructure requirements: Estimating road and railway infrastructure capacity and costs to 2050. Paris: International Energy Agency.

FAO 2016. The State of the World's Forests. Forests and agriculture: land use challenges and opportunities. Rome: FAO.

FAO 2018. The State of the World's Forests. Forest pathways to sustainable development. Rome: FAO.

Geist, H. J. and Lambin, E. F. 2002. Proximate causes and underlying driving forces of tropical deforestation. Bioscience 52(2):143-50.

Gonzalez, J. P., Ar Gouilh, M. Reynes, J. M. and Leroy, E. 2008. Bat-Borne Viral Diseases. In Colfer, C. J. (ed.) Human health and forests: A global overview of issues, practice and policy. London: Earthscan, pp. 161-96.

Henry, R. C. Engstroem, K., Olin, S. et al. 2018. Food supply and bioenergy production within the global cropland planetary boundary. PLoS ONE 13(3): e0194695. https://doi.org/ 10.1371/journal.pone.0194695

Hosonuma, N., Herold, M., De Sy, V. et al. 2012. An assessment of deforestation and forest degradation drivers in developing countries. Environmental Resource Letters 7:044009.

Humphreys, D. 2016. Integers, integrants and normative vectors: The problem of environmental policy integration under neoliberalism. Environment and Planning C: Government and Policy 34 (3):433-447.

International Council for Science 2017. A guide to SDG Interactions: From science to implementation. Paris: ICS.

Katila, P., Galloway, G., de Jong, W., Mery, G., Pacheco, P. (eds.) 2014. Forests under pressure: Local responses to global issues. IUFRO World Series Volume 32. Vienna. IUFRO Special. Available at: www.iufro.org/science/special/wfse/forests-pressure-local-responses/ (Accessed 3 March 2019).

Katila, P., de Jong, W., Galloway, G., Pokorny, B. and Pacheco, P. 2017. Policy brief. Building on synergies: Harnessing community and smallholder forestry for Sustainable Development Goals. Helsinki: IUFRO-WFSE.

Kindornay, S. 2018. Progressing national SDGs implementation: An independent assessment of the voluntary national review reports submitted to the United Nations High-level Political Forum on Sustainable Development in 2017. Ottawa: Canadian Council for International Co-operation.

Kis Madrid, C., Hickey, G. M. and Bouchard, M. A. 2011. Strategic environmental assessment effectiveness and the initiative for the integration of regional infrastructure in South America (IIRSA): A multiple case review. Journal of Environmental Assessment Policy and Management 13(4):515-40. https://doi.org/10.1142/\$1464333211003997.

Krasner, S. D. (ed.) 1983. International Regimes. Ithaca: Cornell University Press.

Le Blanc, D. 2015. Towards integration at last? The Sustainable Development Goals as a network of targets. DESA Working Paper No. 141. ST/ESA/2015/DWP/141

Lin, C. Y. O. 2008. Autonomy Reconstituted: Social and Gendered Implications of Resettlement on the Orang Asli of Peninsular Malaysia. In Resurreccion, B. P. and Elmhirst, R. (eds.) Gender and Natural Resource Management: Livelihoods, Mobility and Interventions. London: Earthscan, pp. 109-26. 
Lopez, P. 2008. The Subversive Links between HIV/AIDS and the Forest Sector. In Colfer, C. J. (ed.) Human health and forests: A global overview of issues, practice and policy. London: Earthscan, pp. 221-37.

Nilsson, M., Griggs, D. and Visbeck, M. 2016. Map the interactions between Sustainable Development Goals. Nature 435:320-2.

Nunes, A. R., Lee, K. and O'Riordan T. 2018. The importance of an integrating framework for achieving the Sustainable Development Goals: the example of health and well-being. BMJ Global Health 2016;1:e000068. doi:10.1136/bmjgh-2016-000068.

OECD 2018. Supporting an integrated implementation of the SDGs: Tools for addressing SDG connections and enhancing policy and institutional coherence. Available at: www.oecd.org/ governance/pcsd/Learning\%20session\%20HLPF\%202018_Tools.pdf (Accessed 3 March 2019).

Oliver, C. and Oliver, F. A. 2018. Global Resources and the Environment. Cambridge: Cambridge University Press.

Pattanayak, S. K. and Yasuoka, J. 2008. Deforestation and Malaria: Revisiting the Human Ecology Perspective. In Colfer, C. J. (ed.) Human Health and Forests: A Global Overview of Issues, Practice and Policy. London: Earthscan, pp. 197-217.

Rolland, N. 2017. China's Eurasian Century? Political and Strategic Implications of the Belt and Road Initiative. National Bureau of Asian Research. Available at: https://muse.jhu.edu/ (Accessed 23 February 019).

Schandl, H., West, J., Baynes, T. and Hosking, K. 2016. Natural Resources and the SDGs: A country snapshot for Malaysia. Canberra: CSIRO.

Scoones, I., Fairhead, J. and Leach, M. 2013. Green Grabbing: A New Appropriation of Nature. The Journal of Peasant Studies 39(2):237-261.

Seymour, F. and Busch, J. 2017. Why forests? Why now? The science, economics and politics of tropical forests and climate change. Washington, DC: Center for Global Development.

Sprinz, D. F. and Helm, C. 1999. The Effect of Global Environmental Regimes: A Measurement Concept. International Political Science Review 20(4): 359-69. https://doi.org/ $10.1177 / 0192512199204003$

Stafford-Smith, M., Griggs, D. Gaffney, O. et al. 2017. Integration: The key to implementing the Sustainable Development Goals. Sustainability Science 12:911-19. DOI 10.1007/s11625016-0383-3.

Sun, Y., Mwangi, E. and Meinzen-Dick, R. 2011. Is Gender an Important Factor Influencing User Groups' Property Rights and Forestry Governance? Empirical Analysis from East Africa and Latin America. International Forestry Review 13(2):205-19.

Swamy, L., Drazen, E., Johnson, W. R. and Bukoski, J. J. 2018. The future of tropical forests under the United Nations Sustainable Development Goals. Journal of Sustainable Forestry 37(2):221-56. doi:10.1080/10549811.2017.1416477.

Waage, J., Yap, C., Bell, S. et al. 2015. Governing Sustainable Development Goals: interactions, infrastructures, and institutions. In Waage, J. and Yap, C. (eds.) Thinking Beyond Sectors for Sustainable Development. London: Ubiquity Press, pp. 79-88. http://dx.doi.org/10.5334/bao.i 